\title{
MR-derived right ventricular parameters can predict pulmonary hypertension
}

\author{
Kayleen Fabini, Amir H Davarpanah, Marie Wasielewski, Jeremy Collins, Timothy J Carroll, Sanjiv J Shah, \\ James C Carr
}

From 2011 SCMR/Euro CMR Joint Scientific Sessions

Nice, France. 3-6 February 2011

\section{Introduction}

Right heart catheterization (RHC) is required for definitive diagnosis of pulmonary hypertension $(\mathrm{PH})$ and serial echocardiograms or RHC are necessary for long term disease management. However, RHC is invasive, costly and risky for the patient[1]. Echocardiography is a non-invasive alternative but recent studies have questioned its accuracy and reproducibility in the setting of $\mathrm{PH}[2]$. Cardiac magnetic resonance (CMR) has been shown to be helpful in distinguishing $\mathrm{PH}$ patients from healthy subjects through visualization of morphologic features such as right atrial and ventricular enlargement, tricuspid regurgitation and abnormal interventricular septal motion[3]. CMR has the additional advantage of producing quantitative measures of right ventricular function, which may have added value in assessing $\mathrm{PH}$.

\section{Purpose}

To evaluate the use of Cardiac MR for measuring right ventricular parameters in order to assess Pulmonary Hypertension.

\section{Methods}

23 patients with $\mathrm{PH}$ and 12 controls underwent CMR on a 1.5T Siemens Avanto scanner. All patients underwent $\mathrm{RHC}$ to diagnose $\mathrm{PH}$ within 1 month of CMR study. The CMR protocol included cine SSFP of the whole heart and phase contrast MRI of the pulmonary valve (PV). The following conventional right ventricular (RV) functional parameters were calculated: ejection fraction (EF), end diastolic volume (EDV) and end systolic volume (ESV). Time to peak systole (TPS), an indirect measure of RV strain, was derived from the volume-time curves of the RV. PV flow analysis was

Northwestern University, Chicago, IL, USA performed and the following parameters were calculated: peak velocity, full-width at half maximum (FWHM), acceleration time (AT) and ejection time (ET).

\section{Results}

The results of RV functional parameters and PV flow values are shown in Tables 1 and 2. TPS was significantly longer for $\mathrm{PH}$ patients $(\mathrm{p}<0.01)$. The shape of the PV flow curve designated by FWHM was also longer in patients $(\mathrm{p}<0.05)$. TPS demonstrated a significant, although relatively weak, correlation with $\mathrm{mPAP}$ $(\mathrm{r}=0.425, \mathrm{p}<0.05)$ and PCWP $(\mathrm{r}=0.435, \mathrm{p}<0.05)$ measurements on RHC. Calculation of the Area Under Curve for TPS gave a value of $0.972(\mathrm{p}<0.001)$ (Figure 1). A cut off value of $42.5 \%$ for TPS had $91.3 \%$ sensitivity and $90.9 \%$ specificity for diagnosis of $\mathrm{PH}$.

Table 1 Cine MR-derived right ventricular parameters in pulmonary hypertension patients and controls

\begin{tabular}{llll}
\hline & Controls & Patients & p-value \\
\hline RV EF $(\mathrm{ml})$ & $46.93 \pm 7.91$ & $37.95 \pm 14.07$ & $<0.05$ \\
EV EDV $(\mathrm{ml})$ & $197.50 \pm 49.73$ & $192.80 \pm 65.04$ & 0.83 \\
RV ESV $(\mathrm{ml})$ & $106.39 \pm 35.94$ & $127.80 \pm 50.83$ & 0.21 \\
RV SV $(\mathrm{ml})$ & $91.12 \pm 21.01$ & $69.63 \pm 32.49$ & $<0.05$ \\
TPS $(\%)$ & $37 \pm 4$ & $51 \pm 7$ & $<0.01$ \\
\hline
\end{tabular}

Table 2 Phase contrast MR-derived pulmonary flow parameters in pulmonary hypertension patients and controls

\begin{tabular}{llll}
\hline & Controls & Patients & p-value \\
\hline FWHM (\%) & $35 \pm 6$ & $45 \pm 7$ & $<0.05$ \\
Velocitymax(cm/s) & $67.5 \pm 3.3$ & $75.3 \pm 23$ & 0.54 \\
AT (\%) & $17 \pm 2$ & $19 \pm 3$ & 0.63 \\
ET (\%) & $46 \pm 6$ & $48 \pm 3$ & 0.41 \\
AT/ET & $0.37 \pm 0.03$ & $0.41 \pm 0.07$ & 0.15
\end{tabular}




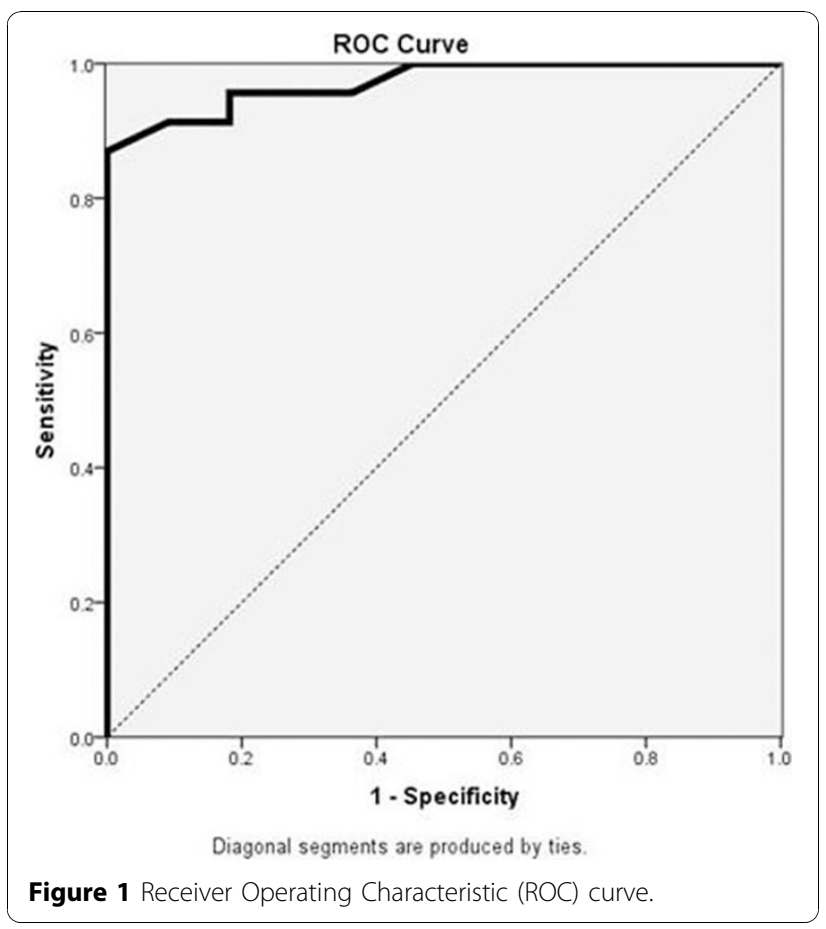

\section{Conclusions}

TPS, calculated by CMR, may be a useful additional quantitative measure for diagnosis of $\mathrm{PH}$ and may be of value in long-term non-invasive assessment of treatment efficacy.

Published: 2 February 2011

\section{References}

1. Hoeper MM, et al: JACC 2006.

2. Nathan SD, et al: Respir Med 2008.

3. Gothues F, et al: AHJ 2004.

doi:10.1186/1532-429X-13-S1-P48

Cite this article as: Fabini et al:: MR-derived right ventricular parameters can predict pulmonary hypertension. Journal of Cardiovascular Magnetic Resonance 2011 13(Suppl 1):P48.
Submit your next manuscript to BioMed Central and take full advantage of:

- Convenient online submission

- Thorough peer review

- No space constraints or color figure charges

- Immediate publication on acceptance

- Inclusion in PubMed, CAS, Scopus and Google Scholar

- Research which is freely available for redistribution

Submit your manuscript at www.biomedcentral.com/submit
C Biomed Central 